\title{
The validity of psychomotor vigilance tasks of less than 10-minute duration
}

\author{
SYLVIA LOH, NICOLE LAMOND, JILL DORRIAN, GREGORY ROACH, and DREW DAWSON \\ University of South Australia, Woodville, Australia
}

\begin{abstract}
The 10-min psychomotor vigilance task (PVT) has often been used to assess the impact of sleep loss on performance. Due to time constraints, however, regular testing may not be practical in field studies. The aim of the present study was to examine the suitability of tests shorter than 10 min. in duration. Changes in performance across a night of sustained wakefulness were compared during a standard 10-min PVT, the first 5 min of the PVT, and the first 2 min of the PVT. Four performance metrics were assessed: (1) mean reaction time (RT), (2) fastest 10\% of RT, (3) lapse percentage, and (4) slowest $10 \%$ of RT. Performance during the 10-min PVT significantly deteriorated with increasing wakefulness for all metrics. Performance during the first $5 \mathrm{~min}$ and the first $2 \mathrm{~min}$ of the PVT deteriorated in a manner similar to that observed for the whole 10-min task, with all metrics except lapse percentage displaying significant impairment across the night. However, the shorter the task sampling time, the less sensitive the test is to sleepiness. Nevertheless, the 5-min PVT may provide a viable alternative to the 10-min PVT for some performance metrics.
\end{abstract}

The adverse effects of sleep loss on human performance are widespread throughout industries that require shift work. Surveys, observational data, and anecdotal incident reports reveal that shift workers often experience sleep episodes, particularly during night shifts and sustained operations (Kogi \& Ohta, 1975; Samel, Wegmann, \& Vejvoda, 1995; Torsvall, Åkerstedt, Gillander, $\&$ Knutsson, 1989). Even when actual sleep episodes do not occur, the underlying physiological state of sleepiness can lead to a deterioration in performance capability. Research indicates, for example, that as sleepiness increases, alertness and vigilance deteriorate, problemsolving and reasoning abilities become slower, psychomotor skills decline, and the rate of false responding increases (Belenky et al., 2003; Buck, 1976; Graeber, 1982; Mullaney, Kripke, Fleck, \& Johnson, 1983; Wimmer, Hoffmann, Bonato, \& Moffitt, 1992). In turn, this can lead to increased error and greater risk of accident, and, ultimately, can threaten work safety.

Although the impact of sleepiness on performance is acknowledged, the availability of objective data concerning its effects on individuals engaged in 24-h operations (e.g., the transport, mining, and health care industries) is limited. This deficiency in data may be attributed to the lack of a suitable and practical assessment tool. Although many performance measures have been validated within laboratory settings, they are not necessarily suitable for use within the workplace. Ideally, a tool for assessing performance in the field should present minimal inter-

Address all correspondence to S. Loh, Centre for Sleep Research, 5th Floor, Basil Hetzel Institute, Queen Elizabeth Hospital, Woodville Road, Woodville, SA 5011, Australia (e-mail: sylvia.loh@atsb.gov.au). ference with the duties of the worker and the work environment. It should also be portable, brief, and devoid of practice or learning effects (Dinges \& Powell, 1985; Rosekind, Gregory, Co, Miller, \& Dinges, 2000). One particular test that meets these requirements is the psychomotor vigilance task (PVT; Wilkinson \& Houghton, 1982).

Typically set at a standard duration of $10 \mathrm{~min}$, the PVT is a sustained-attention, reaction-timed task that is portable and simple to use. Enclosed in a plastic case, the device measures the speed with which subjects respond to a visual stimulus (by pressing a response button). The PVT has become a standard laboratory tool for the assessment of sustained performance in a variety of experimental conditions. These include, for example, partial sleep loss (Dinges \& Powell, 1988, 1989), chronic sleep restriction (Belenky et al., 2003; Dinges et al., 1997; Van Dongen, Maislin, Mullington, \& Dinges, 2003), and napping (Dinges, 1992; Dinges, Orne, Whitehouse, \& Orne, 1987).

Although the PVT is a methodologically reliable and relatively versatile test, 10 -min testing may not always be practical within demanding, time-constrained work environments (e.g., aircraft flight decks, air traffic control rooms). Indeed, in a study on the effects of cockpit napping on pilot alertness (Rosekind et al., 1994), the authors noted that regular in-flight psychomotor vigilance testing was significantly restricted due to operational demands. In consideration of this, in the present study we propose that a test of shorter duration would provide researchers with a more suitable tool, particularly if regular testing is required. To date however, PVT tasks of less than 10-min duration have not been assessed.

Previous studies indicate that shortening a performance task can result in reduced sensitivity (Mullaney et al., 1983; Wilkinson, 1968). Indeed, some researchers 
contend that it is difficult to show reliable changes in performance during short-term sleep loss using tasks that are shorter than 10 min (Bjerner, 1949; Bonnet, 1989). However, the effects of sleep loss have been observed using simple reaction time (RT) tasks of considerably shorter duration (Dawson \& Reid, 1997; Heslegrave \& Angus, 1985). For example, Heslegrave and Angus demonstrated that a serial RT task of only $1 \mathrm{~min}$ in duration was sensitive to the effects of sleep loss. In addition, in previous research conducted in our laboratory, the effects of sleep loss were detected using a 90-sec tracking task (Dawson \& Reid, 1997). Despite being ideal in duration, these particular tasks required a relatively large amount of space and entailed video display terminals and frequent testing. As a result, they are unsuitable for use within confined operational settings found within many transport and industrial environments.

To determine whether a task less than $10 \mathrm{~min}$ in duration may be sensitive to the effects of sleep loss, we compared performance during the first $2 \mathrm{~min}$ and the first 5 min of a 10-min PVT with performance during the entire 10-min task. The analysis of performance during the first $2 \mathrm{~min}$ and the first $5 \mathrm{~min}$ of the task was used as a proxy for actual 2-min and 5-min PVTs. It was hypothesized that performance during the first half of a 10 -min PVT would deteriorate as a result of sleep loss.

\section{METHOD}

\section{Subjects}

Fifteen young healthy subjects ( 7 males and 8 females) volunteered for the present study in response to advertisements displayed at local universities. The subjects were between the ages of 18 and 27 years $(M=21.9, S D=2.7)$ years, with an average body mass index of $22.3 \pm 2.3 . \mathrm{kg} / \mathrm{m}^{2}$. The subjects were nonsmokers, did not regularly consume excessive quantities of caffeine $(<350 \mathrm{mg} /$ day $)$ or alcohol ( $\leq 6$ drinks/week), and exercised regularly. In addition, they reported no history of health or sleep problems, did not habitually nap, and had not undertaken shift work or transmeridian travel in the past month. All of the subjects gave their written, informed consent. Ethics approval for the study was granted by the University of South Australia's Human Research Ethics Committee and the Ethics of Human Research Committee of Queen Elizabeth Hospital.

\section{Procedure}

Reported in the present study are data from the first night (2300 $0600 \mathrm{~h}$ ) of a larger study in which the effects of a week of simulated night work were assessed (Dorrian et al., 2000; Lamond et al., 2003; Lamond et al., 2000). As can be seen in Figure 1, all of the subjects were required to attend one adaptation night and one base- line night, to ensure adjustment to the laboratory environment and consistency of bedtimes and wake-up times. This was immediately followed by a night of wakefulness.

The night of wakefulness commenced with all of the subjects arriving at the laboratory by $1900 \mathrm{~h}$. From $2000 \mathrm{~h}$ onward, all the subjects were confined to the living quarters, where they were allowed to read, watch television, study, listen to music, and play games. As part of a test battery, a 10-min performance test was completed at hourly intervals, commencing at $2300 \mathrm{~h}$ and ending at $0600 \mathrm{~h}$. During the intervening periods, the subjects were free to continue their activities in the living quarters. They were permitted but not required to snack every $2 \mathrm{~h}$ following the testing session of that hour. However, during the testing period, the subjects were required to abstain from caffeine and other stimulants. In addition, they were requested not to exercise, shower, sleep, or leave the living quarters until the final testing session was completed.

\section{Apparatus}

Visual RT was assessed using the PVT-192 (Ambulatory Monitoring Inc., Ardsley, NY). The PVT was enclosed in a plastic case that measured $21 \times 11 \times 6 \mathrm{~cm}$ and weighed $658 \mathrm{~g}$. The upper surface contained a four-digit light-emitting diode (LED) display measuring $2.5 \times 1 \mathrm{~cm}$, an alphanumeric liquid crystal display measuring $6 \times 2 \mathrm{~cm}$, and two push-button response keys measuring $1.1 \times$ $1.1 \mathrm{~cm}$. The LED display was used as the visual RT stimulus and gave performance feedback.

The task is based on a simple visual RT test apparatus originally developed by Wilkinson and Houghton (1982). This task has been shown to be sensitive to sleep deprivation, partial sleep loss, and circadian effects in RT performance (Dinges et al., 1987; Dorrian et al., 2003; Jewett, Dijk, Kronauer, \& Dinges, 1999). In addition, it has a learning curve of only 1-3 trials (Dinges et al., 1997). The microcomputer software system that inputs, edits, transforms, analyzes, and reduces the RT data was developed by Dinges and Powell (1985). For a detailed description of the task, readers are directed to the original study by Dinges and Powell (1985).

The PVT ran for a period of $10 \mathrm{~min}$. The subjects were required to respond to a visual stimulus presented at a variable interval $(2,000-10,000 \mathrm{msec})$ by pressing either the right or the left pushbutton with the thumb of the dominant hand. The visual stimulus was the four-digit LED counter turning on and incrementing from 0 to $60 \mathrm{sec}$ at $1-\mathrm{msec}$ intervals. In response to the subject's buttonpress, the LED counter display stopped incrementing, allowing the subject $1 \mathrm{sec}$ to read his or her RT before the counter restarted. If a response had not been made in $60 \mathrm{sec}$, the clock reset and the counter restarted. If a response was made prior to presentation of the stimulus, a "false start" (FS) message was displayed. If the button was not released after $3 \mathrm{sec}$, a reminder message (RELEASE BUTTON) was displayed.

\section{Statistical Analysis}

The data were analyzed using the REACT data analysis software for the PVT-192 (Ambulatory Monitoring, Inc.). In an attempt to in-

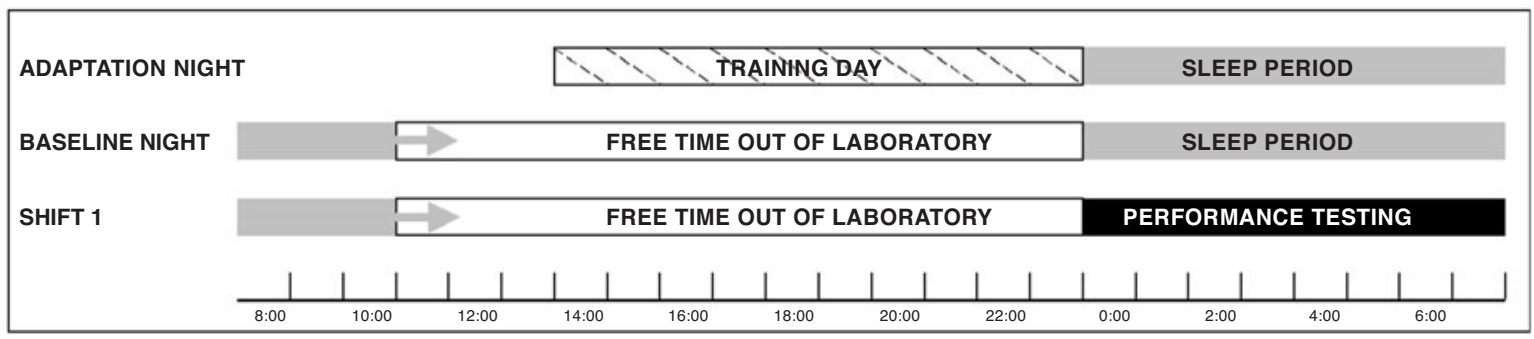

Figure 1. Schematic representation of the research protocol for the night-of-wakefulness experiment. 
clude the most common PVT performance metrics reported in previous studies using the PVT, four different metrics were examined: (1) mean RT, the mean response times for all trials; (2) optimum response domain, the fastest $10 \%$ of response times for all trials (i.e., fastest $10 \% \mathrm{RT}$ ); (3) percentage of lapses, the percentage of response times greater than or equal to $500 \mathrm{msec}$ for all trials (i.e., lapse \%); and (4) lapse domain, the slowest $10 \%$ of reciprocal response times for all trials (i.e., slowest $10 \% 1 / \mathrm{RT}$ ). For this metric, a reciprocal transformation was applied to the raw data in accordance with standard methodology (Dinges \& Kribbs, 1991). This procedure substantially decreases the contribution of long lapses and emphasizes slowing in the optimum and intermediate ranges of responses (Dinges et al., 1987).

The performance metrics were calculated for the whole 10-min PVT, the first $5 \mathrm{~min}$ of the task, and the first $2 \mathrm{~min}$ of the task. For each of these measures of time on task, the effects of time on the four dependent performance metrics were determined using separate repeated measures analyses of variance (ANOVAs). Each ANOVA had one within-subjects factor: time of day $(2300,0000,0100,0200$, 0300, 0400, 0500, and $0600 \mathrm{~h}$ ).

To compare performance in the first $5 \mathrm{~min}$ with that in the whole 10-min PVT, separate repeated measures ANOVAs with two within-subjects factors - time on task (5 $\mathrm{min}$ and $10 \mathrm{~min})$ and time of day $(2300 \mathrm{~h}, 0000 \mathrm{~h}, 0100 \mathrm{~h}, 0200 \mathrm{~h}, 0300 \mathrm{~h}, 0400 \mathrm{~h}, 0500 \mathrm{~h}$, and $0600 \mathrm{~h}$ ) - were conducted. These analyses were then repeated to compare performance in the first 2 min with that in the whole 10min PVT. All missing values were replaced by the group mean. All $p$ values were corrected for sphericity using Greenhouse-Geisser epsilon.

\section{RESULTS}

\section{Mean Reaction Time}

Separate repeated measures ANOVAs indicated that time of day had a significant effect on mean RT for the whole $10 \mathrm{~min}[F(7,98)=26.1, p<.05]$, the first $5 \mathrm{~min}$ $[F(7,98)=17.4, p<.05]$, and the first $2 \min [F(7,98)=$ 9.32, $p<.05$ ] of the task (Table 1, Figure 2).

For the comparison of the first 5 min with the whole 10 min of the PVT, repeated measures ANOVAs indicated that mean RT was significantly affected by time on task $[F(1,14)=48.84, p<.05]$ and time of day $[F(7,98)=$ $22.86, p<.05]$. A significant interaction $[F(7,98)=3.79$, $p<.05]$ indicated that the effect of time of day was greater for the 10-min task than it was for the first 5 min of the task; thus, the difference in RT between the two tasks was greater at the end of the night of wakefulness than it was at the start (Table 2).

For the comparison of the first 2 min with the whole $10 \mathrm{~min}$ of the PVT, repeated measures ANOVAs indi-

Table 1

Summary of ANOVA Results for the Whole 10 Min, the First 5 Min, and the First 2 Min of the PVT

\begin{tabular}{lrrrrrrrr}
\hline & \multicolumn{2}{c}{$10-$ Min PVT } & & \multicolumn{2}{c}{ First 5 Min } & & \multicolumn{2}{c}{ First 2 Min } \\
\cline { 2 - 3 } \multicolumn{1}{c}{ Metric } & $F(7,98)$ & $p^{\text {a }}$ & & $F(7,98)$ & $p^{\text {a }}$ & & $F(7,98)$ & $p^{\text {a }}$ \\
\hline Mean RT & 26.10 & .0001 & & 17.40 & .0001 & & 9.32 & .0001 \\
Fastest 10\% RT & 10.51 & .0001 & & 7.27 & .0003 & & 6.05 & .0014 \\
Lapse \%b & 4.03 & .0355 & & 1.70 & .2016 & & 1.71 & .2057 \\
Slowest 10\% RT & 13.72 & .0001 & & 11.84 & .0001 & & 5.36 & .0001 \\
\hline
\end{tabular}

Note- ${ }^{\mathrm{a}}$ Corrected by Greenhouse-Geisser epsilon. ${ }^{\mathrm{b}}$ First $2 \mathrm{~min}=$ $F(7,91)$. ${ }^{\mathrm{c} A N O V A}$ conducted on transformed data (1/RT). cated that mean RT was significantly affected by time on task $[F(1,14)=39.19, p<.05]$ and time of day $[F(7,98)=$ $19.88, p<.05]$. A significant interaction $[F(7,98)=3.49$, $p<.05]$ indicated that the effect of time of day was greater for the 10-min task than it was for the first $2 \mathrm{~min}$ of the task; thus, the difference in RT between the two tasks was greater at the end of the night of wakefulness than it was at the start (Table 3).

\section{Optimum Response Domain}

Separate repeated measures ANOVAs indicated that time of day had a significant effect on optimum responses for the whole $10 \min [F(7,98)=10.51, p<.05]$, the first $5 \min [F(7,98)=7.27, p<.05]$, and the first $2 \mathrm{~min}$ $[F(7,98)=6.05, p<.05]$ of the task (Table 1, Figure 3 ).

For the comparison of the first 5 min with the whole 10 min of the PVT, repeated measures ANOVAs indicated that time on task $[F(1,14)=5.16, p<.05]$ and time of day $[F(7,98)=9.27, p<.05]$ both had significant effects on optimum responses. Their interaction, however, did not significantly affect optimum responses $[F(7,98)=2.27$, n.s.; see Table 2].

For the comparison of the first 2 min with the whole 10 min of the PVT, repeated measures ANOVAs indicated that time on task $[F(1,14)=5.51, p<.05]$ and time of day $[F(7,98)=9.18, p<.05]$ had significant effects on optimum responses. Their interaction, however, did not significantly affect optimum responses $[F(7,98)=1.15$, n.s.; see Table 3].

\section{Percentage of Lapses}

Separate repeated measures ANOVAs indicated that time of day had a significant effect on the percentage of lapses for the whole $10 \mathrm{~min}$ of the task $[F(7,98)=4.03$, $p<.05]$. In contrast, the first $5 \min [F(7,98)=1.7$, n.s. $]$ and the first $2 \min [F(7,98)=1.71$, n.s. $]$ of the task did not vary significantly (Table 1 , Figure 4).

For the comparison of the first 5 min with the whole 10 min of the PVT, repeated measures ANOVAs indicated that time on task $[F(1,14)=15.07, p<.05]$ had a significant effect on the percentage of lapses. However, neither time of day $[F(7,98)=2.88$, n.s. $]$ nor the interaction $[F(7,98)=2.87$, n.s. $]$ significantly affected the percentage of lapses (Table 2).

For the comparison of the first 2 min with the whole 10 min of the PVT, repeated measures ANOVAs indicated that time on task $[F(1,14)=5.45, p<.05]$ had a significant effect on the percentage of lapses. However, neither time of day $[F(7,98)=3.25$, n.s. $]$ nor the interaction $[F(7,98)=2.95$, n.s. $]$ significantly affected the percentage of lapses (Table 3 ).

\section{Lapse Domain}

Separate repeated measures ANOVAs indicated that time of day had a significant effect on responses in the lapse domain for the whole $10 \min [F(7,98)=13.72, p<$ $.05]$, the first $5 \min [F(7,98)=11.84, p<.05]$, and the first $2 \min [F(7,98)=5.36, p<.05]$ of the task (Table 1 , Figure 5). 


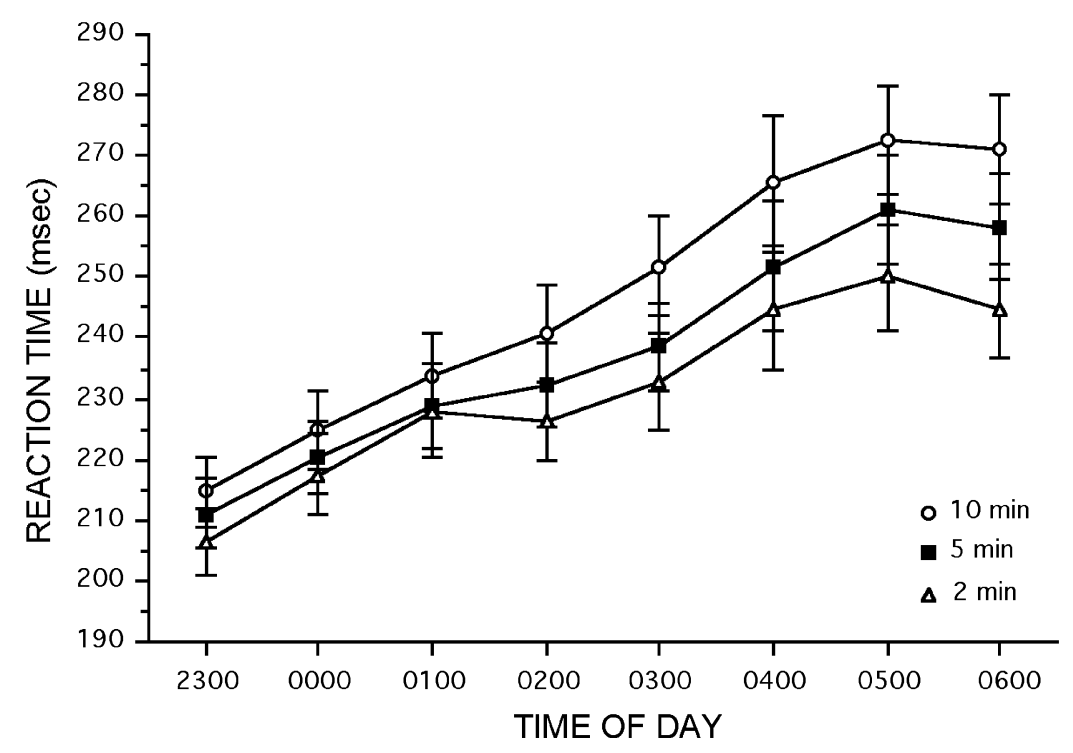

Figure 2. Mean reaction times during the whole $10 \mathrm{~min}$, the first $5 \mathrm{~min}$, and the first 2 min of the PVT. Error bars represent $95 \%$ confidence intervals.

For the comparison of the first 5 min with the whole 10 min of the PVT, repeated measures ANOVAs indicated that time on task $[F(1,14)=21.7, p<.05]$ and time of day $[F(7,98)=14.88, p<.05]$ both had significant effects on responses in the lapse domain. Their interaction, however, did not significantly affect responses in the lapse domain $[F(7,98)=1.28$, n.s.; see Table 2].

For the comparison of the first 2 min with the whole 10 min of the PVT, repeated measures ANOVAs indicated that time on task $[F(1,14)=26.76, p<.05]$ and time of day $[F(7,98)=12.65, p<.05]$ had significant effects on responses in the lapse domain. Their interaction, however, did not significantly affect responses in the lapse domain $[F(7,98)=1.63$, n.s.; see Table 3].

\section{DISCUSSION}

In line with previous research, in the present study we found that psychomotor vigilance performance during the 10-min PVT deteriorated with increasing wakefulness (Dinges \& Powell, 1988, 1989). Specifically, mean RTs, optimum responses, and responses in the lapse domain slowed, whereas the percentage of lapses increased. For each metric, the poorest performance generally occurred at $0500 \mathrm{~h}$, corresponding to the timing of the circadian trough (i.e., 0400-0600 h; Rosa et al., 1990). Similar time-of-day effects have been observed in other studies using the 10-min PVT (Dinges \& Powell, 1989; Lamond et al., 2003). Presumably due to circadian variation in neurobehavioral performance and/or end-of-test effects, performance tended to improve from $0600 \mathrm{~h}$ onward (Bonnet, 1982; Dinges \& Kribbs, 1991; Folkard, 1983).

To determine whether a PVT of less than 10-min duration is sensitive to the effects of sleep loss, performance in the first $5 \mathrm{~min}$ and in the first $2 \mathrm{~min}$ of the PVT was compared with performance in the whole $10 \mathrm{~min}$ of the task. Examination of mean RTs provided a general measure of performance capability. The results indicated that RTs significantly declined across the night during the first $5 \mathrm{~min}$ and the first $2 \mathrm{~min}$ of the 10-min PVT. This deterioration in performance was similar to that observed for the whole 10-min PVT, with the poorest performance generally occurring at $0500 \mathrm{~h}$. It is evident from the significant interaction effect, however, that the

Table 2

Summary of ANOVA Results for the Comparison of the Whole 10 Min and the First 5 Min of the PVT

\begin{tabular}{|c|c|c|c|c|c|c|}
\hline \multirow[b]{3}{*}{ Metric } & \multicolumn{6}{|c|}{ 10-Min PVT - First 5 Min } \\
\hline & \multicolumn{2}{|c|}{ Time on Task } & \multicolumn{2}{|c|}{ Time of Day } & \multicolumn{2}{|c|}{ Interaction } \\
\hline & $F(1,14)$ & $p^{\mathrm{a}}$ & $F(7,98)$ & $p^{\mathrm{a}}$ & $F(7,98)$ & $p^{\mathrm{a}}$ \\
\hline Mean RT & 48.84 & .0001 & 22.86 & .0001 & 3.79 & .0078 \\
\hline Fastest $10 \% \mathrm{RT}$ & 5.16 & .0394 & 9.27 & .0001 & 2.27 & .0673 \\
\hline Lapse \% & 15.07 & .0017 & 2.88 & .0869 & 2.87 & .0518 \\
\hline Slowest $10 \% \mathrm{RT}^{\mathrm{b}}$ & 21.70 & .0004 & 14.88 & .0001 & 1.28 & .2914 \\
\hline
\end{tabular}

Note- ${ }^{\mathrm{a} C}$ Corrected by Greenhouse-Geisser epsilon. ${ }^{\mathrm{b}}$ ANOVA conducted on transformed data $(1 / \mathrm{RT})$. 
Table 3

Summary of ANOVA Results for the Comparison of the Whole 10 Min and the First 2 Min of the PVT

\begin{tabular}{|c|c|c|c|c|c|c|}
\hline \multirow[b]{3}{*}{ Metric } & \multicolumn{6}{|c|}{ 10-Min PVT - First 2 Min } \\
\hline & \multicolumn{2}{|c|}{ Time on Task } & \multicolumn{2}{|c|}{ Time of Day } & \multicolumn{2}{|c|}{ Interaction } \\
\hline & $F(1,14)$ & $p^{\mathrm{a}}$ & $F(7,98)$ & $p^{\mathrm{a}}$ & $F(7,98)$ & $p^{\mathrm{a}}$ \\
\hline Mean RT & 39.19 & .0001 & 19.88 & .0001 & 3.49 & .0118 \\
\hline Fastest $10 \%$ RT & 5.51 & .0341 & 9.18 & .0001 & 1.15 & .3409 \\
\hline Lapse $\%$ b & 5.45 & .0363 & 3.25 & .0768 & 2.95 & .05 \\
\hline Slowest $10 \% \mathrm{RT}^{\mathrm{c}}$ & 26.76 & .0001 & 12.65 & .0001 & 1.63 & .186 \\
\hline
\end{tabular}

Note- ${ }^{a}$ Corrected by Greenhouse-Geisser epsilon. ${ }^{\text {b Task }}=F(1,13)$; Time $=F(7,91)$; Interaction $=F(7,91)$. ${ }^{\mathrm{c}}$ ANOVA conducted on transformed data $(1 / \mathrm{RT})$.

first $2 \mathrm{~min}$ and the first $5 \mathrm{~min}$ were differentially affected by increasing sleep loss in comparison with the whole 10-min test. Specifically, the shorter the task sampling time, the less sensitive the test was to sleepiness. Indeed, visual inspection of mean RTs (Figure 2) clearly shows that performance in the first 2 min was least sensitive to the effects of sleep loss, whereas performance in the whole 10-min task was most affected.

One of the most notable studies of sleep loss, conducted by Williams, Lubin, and Goodnow (1959), suggests that the progressive deterioration in performance during periods of sustained wakefulness is an inevitable effect of lapsing (i.e., the lapse hypothesis). This theory provides a partial explanation for the decrease in average RTs. Moreover, by emphasizing the significance of lapsing in sleep research, this theory justifies the importance of determining whether a PVT of less than 10-min duration is sensitive to lapsing. In the present study, the 10min PVT revealed a substantial increase in lapsing with increasing wakefulness. In contrast, the percentage of lapses detected during the first $5 \mathrm{~min}$ and the first $2 \mathrm{~min}$ of the task did not vary significantly. Indeed, it is clear that the percentage of lapses did substantially decrease with decreasing time on task. Thus, whereas previous studies suggest that lapses increase in frequency and length irrespective of task duration (e.g., $10 \mathrm{~min}$ vs. $30 \mathrm{~min}$; Williams et al., 1959), this is not necessarily the case for tasks shorter than $10 \mathrm{~min}$. Rather, it is apparent from the present study that PVT tests shorter than $10 \mathrm{~min}$ may not detect changes in lapse frequency that result from acute sleep loss.

Although an increase in lapsing was not observed during either the first $5 \mathrm{~min}$ or the first $2 \mathrm{~min}$ of the PVT, response slowing within the lapse domain was observed. It is likely that the reciprocal transformation applied to the raw data prior to analysis emphasized this effect. This transformation is applied to reduce the proportionality between the standard deviation and the mean, effectively minimizing the contribution of very long lapses (i.e., $>$ 2 sec; Dinges \& Kribbs, 1991). It is hypothesized that performance slowing within the lapse domain (i.e., slowest $10 \% 1 / \mathrm{RT}$ ) occurred because of response slowing

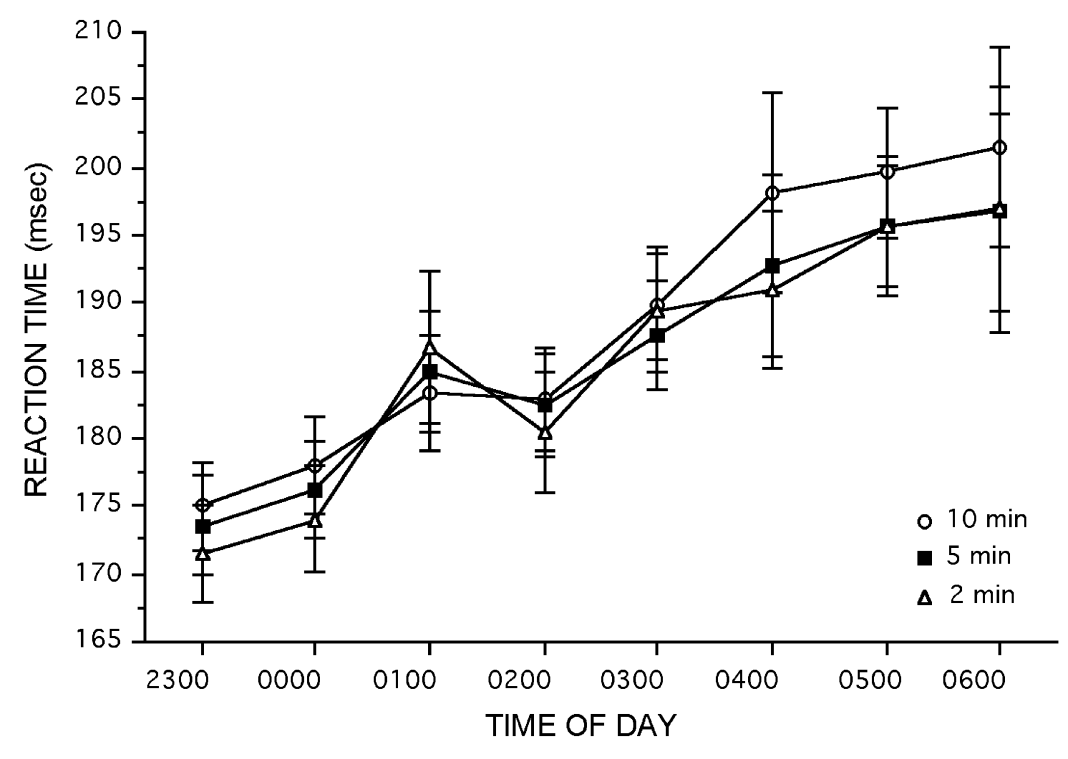

Figure 3. Optimum response domain (i.e., fastest $10 \%$ of reaction times per trial) during the whole $10 \mathrm{~min}$, the first $5 \mathrm{~min}$, and the first $2 \mathrm{~min}$ of the PVT. Error bars represent $95 \%$ confidence intervals. 


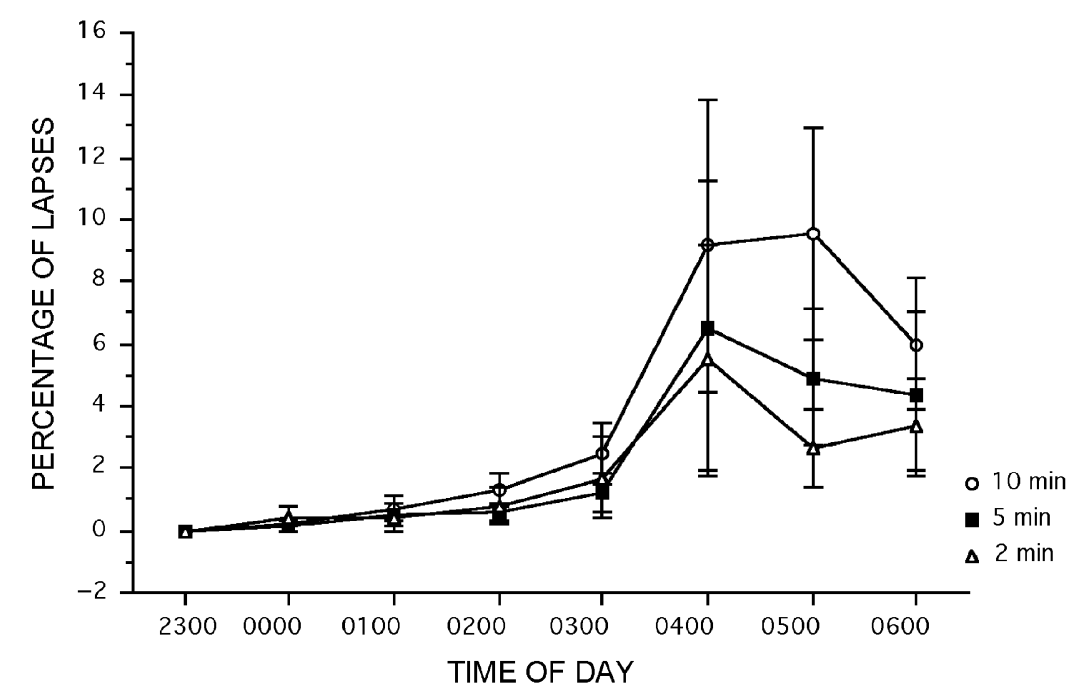

Figure 4. Percentage of lapses during the whole $10 \mathrm{~min}$, the first $5 \mathrm{~min}$, and the first 2 min of the PVT. Error bars represent $95 \%$ confidence intervals.

within the intermediate RT domain (i.e., $300-500 \mathrm{msec}$ ). Thus, although tasks shorter than 10 min may not be highly sensitive to lapsing, they may still provide a measure of the response slowing that occurs within the more intermediate range of performance capability.

In general, humans tend to demonstrate more consistent performance within the optimal response domain, so that deterioration in performance is less likely to be observed in the fastest $10 \%$ of RTs. However, as several authors (Dinges \& Powell, 1989; Lisper \& Kjellberg, 1972; Williams et al., 1959) have recognized, it is still possible for sleep loss to cause a significant deterioration in optimum response speeds. Indeed, this was demonstrated in the present study, in which the fastest $10 \%$ of responses showed a steady decline across the night, in- dependent of time on task. Importantly, the declines in performance during the first $5 \mathrm{~min}$ and the first $2 \mathrm{~min}$ of the PVT closely paralleled that observed in the whole 10 min of the PVT.

In accordance with previous studies (Belenky et al., 2003; Dinges \& Powell, 1988, 1989), the fact that optimum responses slowed clearly indicates that lapses do not fully account for the performance decrements observed in the present study. Rather, it is apparent from the changes in the optimum response domain that performance impairment is also the result of a general slowing of all responses. This finding is similar to that originally observed in a study by Dinges and Powell (1988), who demonstrated that response deceleration with time on task systematically increased with sleepiness, irre-

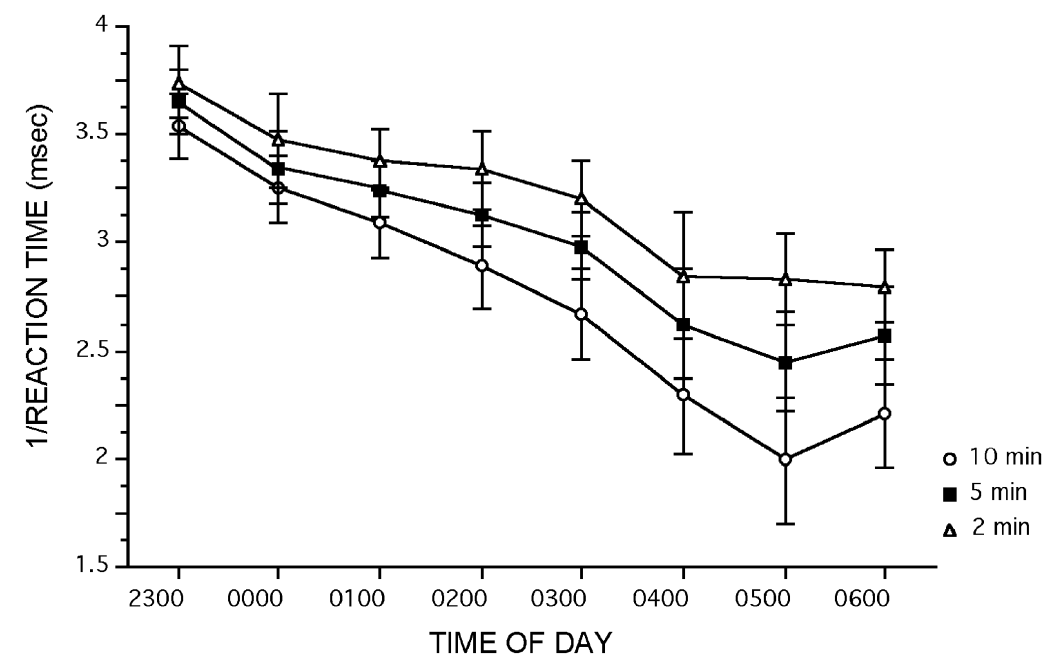

Figure 5. Lapse domain (i.e., slowest $10 \%$ of reaction times per trial) during the whole $10 \mathrm{~min}$, the first $5 \mathrm{~min}$, and the first 2 min of the PVT. Error bars represent $95 \%$ confidence intervals. 
spective of lapsing (i.e., at RT $=200-500 \mathrm{msec}$ ). This suggests that a PVT test of 5-min duration or less will reveal general response slowing during periods of sleep loss.

In summary, the results of this study show that a significant decline in performance was detected during the first $2 \mathrm{~min}$ and the first $5 \mathrm{~min}$ of the 10-min PVT. Specifically, performance deterioration was observed for mean RTs, optimum responses, and responses in the lapse domain. These results support the hypothesis that RTs during the first half of a 10-min PVT are sensitive to the effects of sleep loss. However, as is indicated most clearly by the mean RT metric, sensitivity to sleep loss decreased with decreasing time on task. As a result, the magnitude of change in mean RTs was substantially less for the first $2 \mathrm{~min}$ in comparison with the first $5 \mathrm{~min}$ of the 10 -min PVT. These findings suggest that a PVT set at 5-min duration is likely to provide a more accurate measure of the performance changes observed in a sleepy subject than a PVT set at 2-min duration. Importantly, though, it is predicted that a 5-min PVT will be too short to show a significant increase in lapsing. Thus, in field environments in which time constraints are not of concern, the 10-min PVT would be preferable. In environments in which this is not the case, the results of this study show that the 5min PVT is worthy of consideration and further research.

We recognize that this study is methodologically limited because the first $2 \mathrm{~min}$ and the first $5 \mathrm{~min}$ of the 10 min PVT were used as a proxy for shorter task durations. This approach is problematic because factors such as knowledge of task duration may have confounded or affected the findings. That is, the subjects may have used certain strategies for maintaining performance that were based on the knowledge that the task was 10 min long. During shorter tasks, these strategies may vary. Furthermore, previous research indicates that performance on a longer task may be more fatiguing (Doran, Van Dongen, \& Powell, 2000). Thus, this study may have overestimated the effects of sleep loss on performance during the first half of the 10-min task. Finally, subjects may be more motivated to perform shorter tasks, and this may decrease the sensitivity of such tasks. Indeed, it has been found that motivation can counteract the detrimental effects of sleep loss for up to $36 \mathrm{~h}$ (Horne \& Pettitt, 1985). To address these limitations, future research should be conducted to examine the results of actual PVT tests set at 10-, 5-, and 2-min durations.

\section{REFERENCES}

Belenky, G., Wesensten, N. J., Thorne, D. R., Thomas, M. L., Sing, H. C., Redmond, D. P., Russo, M. B., \& Balkin, T. J. (2003). Patterns of performance degradation and restoration during sleep restriction and subsequent recovery: A sleep dose-response study. Journal of Sleep Research, 12, 1-12.

BJERner, B. (1949). Alpha depression and lowered pulse rate during delayed actions in a serial reaction test: A study of sleep deprivation. Acta Physiologica Scandinavica, 19, 1-93.

Bonnet, M. H. (1982). Performance during sleep. In W. B. Webb (Ed.), Biological rhythms, sleep, and performance (pp. 205-237). Chichester, U.K.: Wiley.
Bonnet, M. H. (1989). Sleep deprivation. In M. H. Kryger, T. Roth, \& W. C. Dement (Eds.), Principles and practice of sleep medicine (pp. 50-67). Philadelphia: Saunders.

BUCK, L. (1976). Psychomotor test performance and sleep patterns of aircrew flying transmeridional routes. Aviation, Space, \& Environmental Medicine, 47, 979-986.

Dawson, D., \& ReID, K. (1997). Fatigue, alcohol and performance impairment. Nature, $\mathbf{3 8 8}, 235$.

DiNGES, D. F. (1992). Adult napping and its effects on ability to function. In C. Stampi (Ed.), Why we nap: Evolution, chronobiology, and functions of polyphasic and ultrashort sleep (pp. 118-134). Boston: Birkhäuser.

Dinges, D. F., \& KRIBBS, N. B. (1991). Performing while sleepy: Effects of experimentally-induced sleepiness. In T. H. Monk (Ed.), Sleep, sleepiness, and performance (pp. 97-128). Chichester, U.K.: Wiley.

Dinges, D. F., Orne, M. T., Whitehouse, W. G., \& Orne, E. C. (1987). Temporal placement of a nap for alertness: Contributions of circadian phase and prior wakefulness. Sleep, 10, 313-329.

Dinges, D. F., Pack, F., Williams, K., Gillen, K. A., Powell, J. W., Otт, G. E., Aptowicz, C., \& PACK, A. I. (1997). Cumulative sleepiness, mood disturbance and psychomotor vigilance performance decrements during a week of sleep restricted to $4-5$ hours per night. Sleep, 20, 267-277.

Dinges, D. F., \& PowelL, J. W. (1985). Microcomputer analyses of performance on a portable, simple visual RT task during sustained operations. Behavior Research Methods, Instruments, \& Computers, 17, 652-655.

Dinges, D. F., \& Powell, J. W. (1988). Sleepiness is more than lapsing. Journal of Sleep Research, 17, 84.

Dinges, D. F., \& Powell, J. W. (1989). Sleepiness impairs optimum response capability - it's time to move beyond the lapse hypothesis. Journal of Sleep Research, 18, 366.

Doran, S. M., Van Dongen, H. P. A., Powell, J. W., Mallis, M. M., Konowal, N. M., \& Dinges, D. F. (2000). Effects of cumulative workload on vigilance decrement during total sleep deprivation. Sleep, 23, A240.

Dorrian, J., Lamond, N., Holmes, A. L., Burgess, H. J., Roach, G. D., Fletcher, A., \& Dawson, D. (2000). The ability to selfmonitor performance: Effects of acute and cumulative partial sleep deprivation. Sleep, 23, A240.

Dorrian, J., Lamond, N., Holmes, A. L., Burgess, H. J., Roach, G. D., Fletcher, A., \& Dawson, D. (2003). The ability to self-monitor performance during a week of simulated night shifts. Sleep, 26, 1-7.

FolKard, S. (1983). Diurnal variation. In R. Hockey (Ed.), Stress and fatigue in human performance (pp. 245-272). Chichester, U.K.: Wiley.

GRAEBER, R. C. (1982). Alterations in performance following rapid transmeridian flight. In F. M. Brown \& R. C. Graeber (Eds.), Rhythmic aspects of behavior (pp. 173-213). Hillsdale, NJ: Erlbaum.

Heslegrave, R. J., \& Angus, R. G. (1985). The effects of task duration and work-session location on performance degradation induced by sleep loss and sustained cognitive work. Behavior Research Methods, Instruments, \& Computers, 17, 592-603.

Horne, J. A., \& Pettitt, A. N. (1985). High incentive effects on vigilance performance during 72 hours of total sleep deprivation. Acta Psychologica, 58, 123-139.

Jewett, M. E., Dijk, D.-J., Kronauer, R., \& Dinges, D. F. (1999). Dose-response relationship between sleep duration and human psychomotor vigilance and subjective alertness. Sleep, 22, 171-179.

KoGI, K., \& OHTA, T. (1975). Incidence of near accidental drowsing in locomotive driving during a period of rotation. Journal of Human Ergology, 4, 65-76.

Lamond, N., Dorrian, J., Roach, G. D., McCulloch, K., Holmes, A. L., Burgess, H. J., Fletcher, A., \& Dawson, D. (2003). The impact of a week of simulated night work on sleep, circadian phase, and performance. Occupational \& Environmental Medicine, 60, $13 \mathrm{e}$.

Lamond, N., Dorrian, J., Holmes, A. L., Burgess, H. J., Roach, G. D., Fletcher, A., \& Dawson, D. (2000). Equating the effects of acute and cumulative partial sleep deprivation on performance. Sleep, 23, A73.

LisPeR, H.-O., \& KJELlBerG, A. (1972). Effects of 24-hour sleep deprivation on rate of decrement in a 10 -minute auditory reaction time task. Journal of Experimental Psychology, 96, 287-290. 
Mullaney, D. J., Kripke, D. F., Fleck, P. A., \& Johnson, L. C. (1983). Sleep loss and nap effects on sustained continuous performance. Psychophysiology, 20, 643-651.

Rosa, R. R., Bonnet, M. H., Bootzin, R. R., Eastman, C. I., Monk, T. H., PenN, P. E., TePas, D. I., \& Walsh, J. (1990). Intervention factors for promoting adjustment to nightwork and shiftwork. Occupational Medicine, 5, 391-415.

Rosekind, M. R., Graeber, R. C., Dinges, D. F., Connell, L. J., Rountree, M. S., Spinweber, C. L., \& Gillen, K. A. (1994). Crew factors in flight operations IX: Effects of planned cockpit rest on crew performance and alertness in long-haul operations (NASA Technical Memorandum 108839). Moffett Field, CA: NASA Ames Research Center.

Rosekind, M. R., Gregory, K. B., Co, E. L., Miller, D. L., \& Dinges, D. F. (2000). Crew factors in flight operations XII: A survey of sleep quantity and quality in on-board crew rest facilities (NASA Technical Memorandum 209611). Moffett Field, CA: NASA Ames Research Center.

Samel, A., Wegmann, H. M., \& Vejvoda, M. (1995). Jet lag and sleepiness in aircrew. Journal of Sleep Research, 4, 30-36.

Torsvall, L., Åkerstedt, T., Gillander, K., \& Knutsson, A. (1989). Sleep on the night shift: 24-hour EEG monitoring of spontaneous sleep/wake behavior. Psychophysiology, 26, 352-358.
Van Dongen, H. P. A., Maislin, G., Mullington, J. M., \& Dinges, D. F. (2003). The cumulative cost of additional wakefulness: Doseresponse effects on neurobehavioral functions and sleep physiology from chronic sleep restriction and total sleep deprivation. Sleep, 26, 117-126.

Wilkinson, R. T. (1968). Sleep deprivation: Performance tests for partial and selective sleep deprivation. In L. E. Abt \& B. F. Reiss (Eds.), Progress in clinical psychology: Dreams and dreaming (pp. 28-43). New York: Grune \& Stratton.

Wilkinson, R. T., \& Houghton, D. (1982). Field test of arousal: A portable reaction timer with data storage. Human Factors, 24, 487 493.

Williams, H. L., Lubin, A., \& Goodnow, J. J. (1959). Impaired performance with acute sleep loss. Psychological Monographs: General \& Applied, 73, 1-26.

Wimmer, F., Hoffmann, R. F., Bonato, R. A., \& Moffitt, A. R. (1992). The effects of sleep deprivation on divergent thinking and attention processes. Journal of Sleep Research, 1, 223-230.

(Manuscript received October 1, 2002; revision accepted for publication October 26, 2003.) 